\title{
Endotracheal instillation of prostacyclin in preterm infants with persistent pulmonary hypertension
}

\author{
A.P.M.C. De Jaegere, J.N. van den Anker
}

\begin{abstract}
Endotracheal instillation of prostacyclin in preterm infants with persistent pulmonary hypertension. A.P.M.C. De Jaegere, J.N. van den Anker. (OERS Journals Ltd 1998.

ABSTRACT: Does endotracheal instilled prostacyclin (epoprostenol) improve oxygenation in preterm infants with persistent pulmonary hypertension?

Four preterm infants were studied. Prostacyclin $\left(50 \mathrm{ng} \cdot \mathrm{kg}^{-1}\right)$ was injected as an endotracheal bolus. In two patients the prostacyclin bolus was repeated and in one patient prostacyclin was administered continuously. Oxygenation was evaluated through the oxygenation index and the ratio of arterial oxygen tension to the fraction of inspired oxygen. The mean arterial blood pressure was used to evaluate systemic circulation.

The oxygenation index $( \pm$ SD) decreased significantly from $39( \pm 13.3)$ to $7( \pm 2.5)$ and the ratio of arterial oxygen tension to the fraction of inspired oxygen $( \pm \mathrm{SD})$ increased significantly from $47( \pm 13)$ to $218( \pm 67)$, most likely related to a reduction of the pulmonary vascular resistance with a reversal of the extrapulmonary shunting at the ductus arteriosus and atrial level. The blood pressure did not change. All effects were reversed on drug withdrawal. Repeated or continuous endotracheal administration of prostacyclin in three children demonstrated a sustained response without tachyphylaxis, and without overt side-effects.

Endotracheal instillation of prostacyclin resulted in an improved oxygenation without systemic vascular repercussions in four preterm infants with persistent pulmonary hypertension. Repeated or continuous administration showed a sustained response and no overt side-effects were noticed.
\end{abstract}

Eur Respir J 1998; 12: 932-934.
Dept of Pediatrics, Division of Neonatology, Erasmus University and University Hospital Rotterdam/Sophia Children's Hospital, Rotterdam, The Netherlands.

Correspondence: A.P.M.C. De Jaegere

Department of Pediatrics

Sophia Children's Hospital

Dr. Molewaterplein 60

3015 GJ Rotterdam

The Netherlands

Fax: 31104636811

Keywords: Endotracheal

persistent pulmonary hypertension

preterm infants

prostacyclin

Received: November 151997

Accepted after revision May 121998
Persistent pulmonary hypertension (PPH) is a clinical syndrome, characterized by a sustained elevation of the pulmonary vascular resistance with a right-to-left shunt across the ductus arteriosus and/or the foramen ovale, causing severe hypoxaemia. Although generally associated with diseases of term newborns PPH has been increasingly described in preterm infants as well [1]. Inhaled nitric oxide (iNO) has been described as an effective selective pulmonary vasodilator improving oxygenation in newborns including preterm infants. However, concern over iNO relates to its potential toxicity and to difficulties in developing safe and effective delivery systems. Intravenous prostacyclin (epoprostenol) is a potent vasodilator in PPH [2]. Nevertheless, its effect on systemic vasculature and on pulmonary vessels of nonventilated areas limits its clinical application. Recently, aerosolized prostacyclin has been reported both in clinical and experimental settings to be a selective pulmonary vasodilator without side-effects on the systemic vasculature [3-5]. No human data on topical epoprostenol-related toxicity are available. In an animal study no signs of acute pulmonary toxicity were shown from prostacyclin inhalation [6]. We here describe the effect of endotracheal instillation of prostacyclin on oxygenation and haemodynamics in four preterm infants with severe pulmonary hypertension.

\section{Patients and methods}

The patients' underlying diseases were hyaline membrane disease (patients 1-3) and septicaemia caused by Escherichia coli (patient 4). Demographic data are listed in table 1 . All patients had an arterial oxygen tension $\left(\mathrm{Pa}, \mathrm{O}_{2}\right) /$ fraction of inspired oxygen $\left(F \mathrm{I}, \mathrm{O}_{2}\right)$ ratio $<70$ despite optimum ventilator settings during at least $6 \mathrm{~h}$. Oxygenation was monitored using pre- and postductal transcutaneous pulse oximetry and a pre- and/or postductal indwelling arterial catheter. The variables measured and calculated were the $\mathrm{Pa}, \mathrm{O}_{2} / F \mathrm{I}, \mathrm{O}_{2}$, the oxygenation index $\left(O \mathrm{I} ;\left(\left(F \mathrm{I}, \mathrm{O}_{2} \times\right.\right.\right.$ mean airway pressure $\left.) /\left(\mathrm{Pa}, \mathrm{O}_{2}\right) \times 100\right)$ and mean systemic arterial blood pressure (MAP). Patients were only enrolled after informed consent was obtained from the parents. In all infants the presumptive diagnosis of persistent pulmonary hypertension was confirmed with air-contrast echocardiography showing a right-to-left shunt across the ductus arteriosus and/or the foramen ovale. The epoprostenol, dissolved in glycine buffer (Flolan ${ }^{\circledR}$, GlaxoWellcome B.V., Zeist, the Netherlands), was diluted with saline ( $\mathrm{NaCl} 0.9 \%$ ) to a concentration of $50 \mathrm{ng} \cdot \mathrm{mL}^{-1}$. The $\mathrm{pH}$ of this solution was 10.3. This epoprostenol solution of $50 \mathrm{ng} \cdot \mathrm{mL}^{-1}$ was instilled as a bolus of $1 \mathrm{~mL} \cdot \mathrm{kg}^{-1}$ endotracheally through a catheter reaching the distal end of the endotracheal tube. 
Table 1. - Patient characteristics

\begin{tabular}{lccc}
\hline $\begin{array}{l}\text { Patient } \\
\text { No. }\end{array}$ & $\begin{array}{c}\text { Gestational age } \\
\text { weeks }\end{array}$ & $\begin{array}{c}\text { Birth weight } \\
\mathrm{g}\end{array}$ & Disease \\
\hline 1 & 30.9 & 845 & HMD \\
2 & 27.1 & 745 & HMD \\
3 & 26.7 & 895 & HMD \\
4 & 33.7 & 2300 & E. coli sepsis \\
\hline
\end{tabular}

HMD: hyaline membrane disease; E. coli: Escherichia coli.

Epoprostenol was administered within 1-2 h after extrapulmonal shunting was established with echocardiogram. In two children the endotracheal instillation of prostacyclin was repeated three times. In a third child, continuous endotracheal administration of $1 \mathrm{~mL} \cdot \mathrm{kg}^{-1} \cdot \mathrm{h}^{-1}$ epoprostenol solution was given for a period of $12 \mathrm{~h}$. Registration of ventilator settings, blood gases and circulatory parameters was carried out just before, $10 \mathrm{~min}$ after, and at $30 \mathrm{~min}$ intervals after administration of prostacyclin.

\section{Results}

We studied the effects of endotracheal instilled prostacyclin in four infants with persistent pulmonary hypertension. The administration of $50 \mathrm{ng} \cdot \mathrm{kg}^{-1}$ prostacyclin as an endotracheal bolus injection decreased the oxygenation index $( \pm \mathrm{sD})$ from $39( \pm 13.3)$ to $7( \pm 2.5)$ (fig. 1b) and increased the ratio of $P \mathrm{a}_{1} \mathrm{O}_{2}$ to $\mathrm{FI}, \mathrm{O}_{2}$ from $47( \pm 13.0)$ to 218 ( \pm 66.6 ) (fig. 1a). Improvement of oxygenation is most likely related to the reduction of the pulmonary vascular resistance and reversal of the extrapulmonary shunting at the ductal and atrial level. The mean systemic arterial blood pressure did not change after prostacyclin instillation (fig. 1c). The endotracheal instillation procedure was well tolerated and no adverse cardiocirculatory events occurred. Effects on oxygenation were reversed on drug withdrawal. Repeated or continuous endotracheal administration of prostacyclin in three infants demonstrated a sustained response without tachyphylaxis and without overt side-effects.

\section{Discussion}

PPH in term and preterm infants is a complex disorder characterized by an altered vasoreactivity with a marked pulmonary hypertension leading to a right-to-left shunting of blood across the patent ductus arteriosus and foramen ovale. Mechanisms for the vascular tone dysregulation are incompletely understood. However, a dysbalance of endogenous vasodilators (such as prostacyclin or endotheliumderived NO) and vasoconstrictors (such as thromboxane $\mathrm{A}_{2}$ ) play a role in this process [7]. In recent years iNO has been shown to improve oxygenation through a selective pulmonary vasodilation without repercussion on the systemic vasculature. Two recent prospective controlled trials demonstrated a reduced incidence of the invasive extracorporeal membrane oxygenation therapy in term newborns suffering PPH, however, without improvement of morbidity and mortality rates [8, 9]. Although major concern exists regarding potential toxicities of $\mathrm{NO}$ and its metabolites, no evidence of immediate toxic effect was found in these studies. PeLIowsKi et al. [10] demonstrated an im-prove-
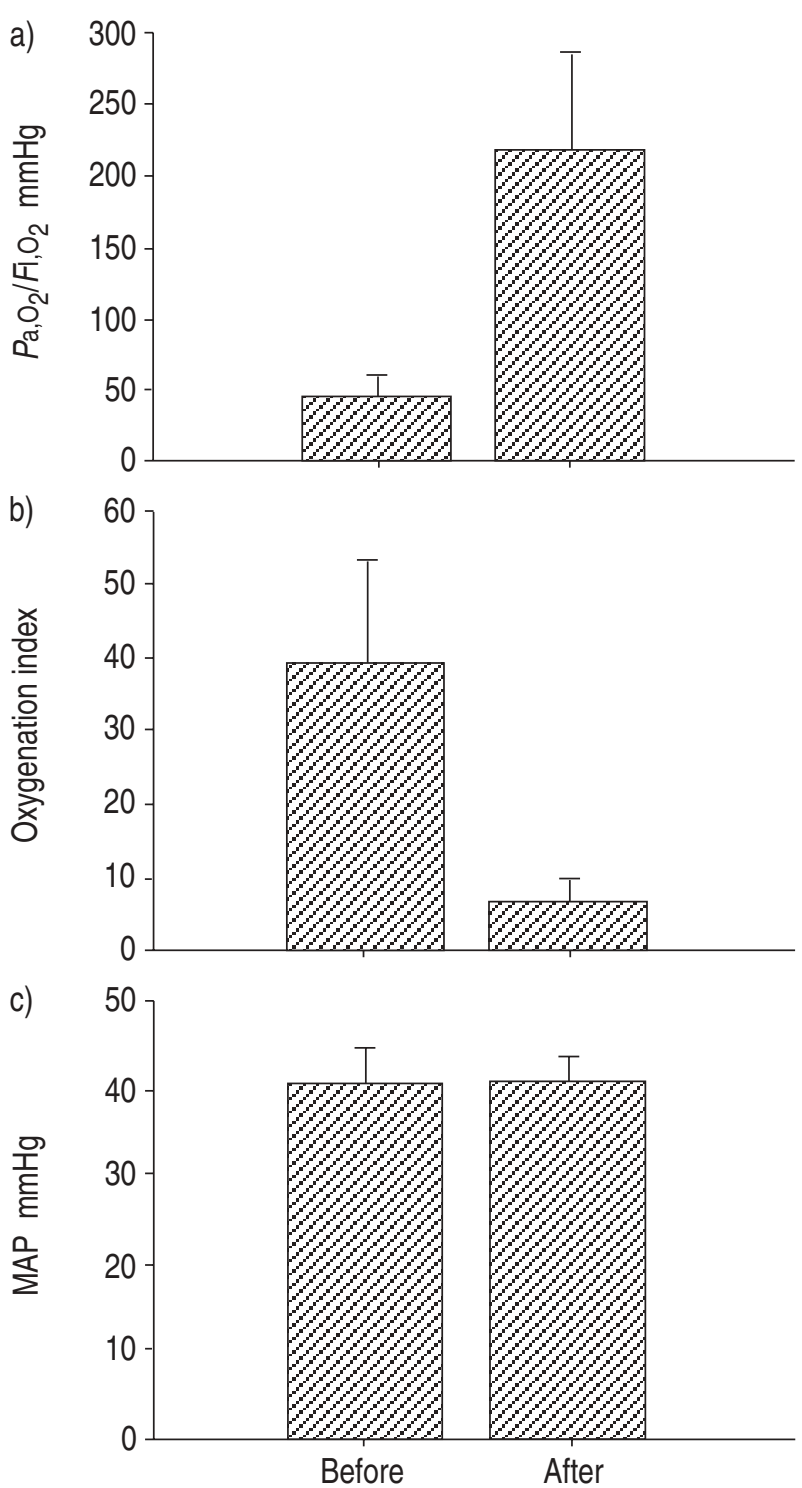

Fig. 1. - a) the arterial oxygen tension $\left(\mathrm{Pa}_{\mathrm{a}} \mathrm{O}_{2}\right)$ /inspiratory oxygen fraction $\left(F \mathrm{I}, \mathrm{O}_{2}\right)$ ratio, b) the oxygenation index and $\left.\mathrm{c}\right)$ the mean arterial blood pressure are all shown before and after endotracheal instillation of a bolus of $50 \mathrm{ng} \cdot \mathrm{kg}^{-1}$ epoprostenol. Data are presented as mean and SD.

ment in oxygenation with inhaled nitric oxide in eight preterm infants. For the preterm infant different considerations and concerns exist regarding toxicity of $\mathrm{NO}$ and its metabolites [11]. Until now no data of prospective controlled trials in this population have been available. Important considerations compared with term newborns are maturational differences in haemoglobin, coagulation, free radical scavenging systems and surfactant metabolism.

Another difficulty in general with iNO is related to a safe and reliable delivery system $[12,13]$. Intravenous prostacyclin is a potent, dose-dependent vasodilator. However, vasodilation is nonselective, resulting in both systemic hypotension and an increase of ventilation/perfusion mismatch in nonventilated areas. Thus, intravenous prostacyclin and inhaled NO are potent pulmonary vasodilators, but each with limitations in clinical application. There- 
fore, WaLmRath et al. [4] studied the effect of prostacyclin aerosol $\left(17-50 \mathrm{ng} \cdot \mathrm{kg}^{-1} \cdot \mathrm{min}^{-1}\right)$ on the lung vasculature in humans. They showed pulmonary vasodilation in three adults with acute respiratory distress syndrome, together with reduced shunt-flow and improved arterial oxygenation, suggesting that the endotracheal route of prostacyclin ap-plication probably allows targeting of prostanoid activity to lung vessels in well-ventilated areas. BINDL et al. [3] and ZWISSLER et al. [14] investigated the effect of endotracheal prostacyclin in three term newborns with PPH [2] and congenital heart disease [1], respectively. They also found an improvement in oxygenation without repercussions on the systemic circulation.

Our data indicate that, in preterm infants who suffer from hyaline membrane disease or sepsis with persistent pulmonary hypertension, endotracheal instillation of 50 ng. $\mathrm{kg}^{-1}$ prostacyclin resulted in a significant improvement of arterial oxygenation by reversal of the extrapulmonal shunting. Repeated endotracheal instillation of $50 \mathrm{ng} \cdot \mathrm{kg}^{-1}$ prostacyclin showed sustained responses. Even continuous administration of $50 \mathrm{ng} \cdot \mathrm{kg}^{-1} \cdot \mathrm{h}^{-1}$ during 12 consecutive hours demonstrated a sustained response without any sign of tachyphylaxis. No negative systemic vascular effects were noticed with this dosage. It is not known whether a higher dosage would result in systemic effects due to resorption of the epoprostenol. For stability reasons epoprostenol is prepared in a glycine buffer ( $\mathrm{pH}$ 10.5). Therefore, concerns can be raised regarding topical application of a highly alkaline solution within the airways of preterm infants. An animal study showed no acute toxicity of endotracheal administered prostacyclin in healthy lambs [6]. However, no data exist on the toxicity of topical epoprostenol in preterm infants and further randomized studies should be performed to investigate differences in toxicities at different strategies using prostacyclin therapy. Zoвel et al. [5] compared inhaled nitric oxide and inhaled prostacyclin as selective pulmonary vasodilators in piglets. They demonstrated an improvement in oxygenation mainly due to improved mismatch of pulmonary perfusion and ven-tilation. In contrast to NO, measurement of the inspired concentration is unnecessary. However, concern exists regarding the deposition of aerolized or instilled medication. The exact dose and mode of administration has to be investigated in further studies. The use of surfactant as a potential carrier of prostacyclin might prove to be a useful alternative in the treatment of pulmonary hypertension in preterm newborns with hyaline membrane disease and pulmonary hypertension.

\section{References}

1. Walther FJ, Benders MJ, Leighton JO. Persistent pulmonary hypertension in premature neonates with severe respiratory distress syndrome. Pediatrics 1992; 90: 899-904.

2. Higenbottam $\mathrm{T}$. The place of prostacyclin in the clinical management of primary pulmonary hypertension. Am Rev Respir Dis 1987; 136: 782-785.

3. Bindl L, Fahnenstich H, Peukert U. Aerosolised prostacyclin for pulmonary hypertension in neonates. Arch Dis Child Fetal Neonatal Ed 1994; 71: F214-216.

4. Walmrath D, Schneider T, Pilch J, Grimminger F, Seeger W. Aerosolised prostacyclin in adult respiratory distress syndrome. Lancet 1993; 342: 961-962.

5. Zobel G, Dacar D, Rodl S, Friehs I. Inhaled nitric oxide versus inhaled prostacyclin and intravenous versus inhaled prostacyclin in acute respiratory failure with pulmonary hypertension in piglets. Pediatr Res 1995; 38: 198-204.

6. Habler O, Kleen M, Zwissler B, et al. Inhalation of prostacyclin (PGI2) for 8 hours does not produce signs of acute pulmonary toxicity in healthy lambs. Intens Care Med 1996; 22: 426-433.

7. Kinsella JP, Abman SH. Recent developments in the pathophysiology and treatment of persistent pulmonary hypertension of the newborn. J Pediatr 1995; 126: 853 864.

8. Roberts JD Jr, Fineman JR, Morin FC III, et al. Inhaled nitric oxide and persistent pulmonary hypertension of the newborn. The Inhaled Nitric Oxide Study Group. $N$ Engl J Med 1997; 336: 605-610.

9. Anonymous. Inhaled nitric oxide in full-term and nearly full-term infants with hypoxic respiratory failure. The Neonatal Inhaled Nitric Oxide Study Group. $N$ Engl $J$ Med 1997; 336: 597-604.

10. Peliowski A, Finer NN, Etches PC, Tierney AJ, Ryan AR. Inhaled nitric oxide for premature infants after prolonged rupture of membranes. J Pediatr 1995; 126: 450453.

11. Skimming JW, Bender KA, Hutchison AA, Drummond WH. Nitric oxide inhalation in infants with respiratory distress syndrome. J Pediatr 1997; 130: 225-230.

12. De Jaegere APMC, Jacobs F, Laheij NDG, van den Anker JN. Variation of inhaled nitric oxide concentration with the use of a continuous flow ventilator. Crit Care Med 1997; 25: 995-1002.

13. Dellinger PR. Inhaled nitric oxide: can we deliver? Intensive Care Med 1997; 23: 933-935.

14. Zwissler B, Rank N, Jaenicke U, et al. Selective pulmonary vasodilation by inhaled prostacyclin in a newborn with congenital heart disease and cardiopulmonary bypass. Anesthesiology 1995; 82: 1512-1516. 